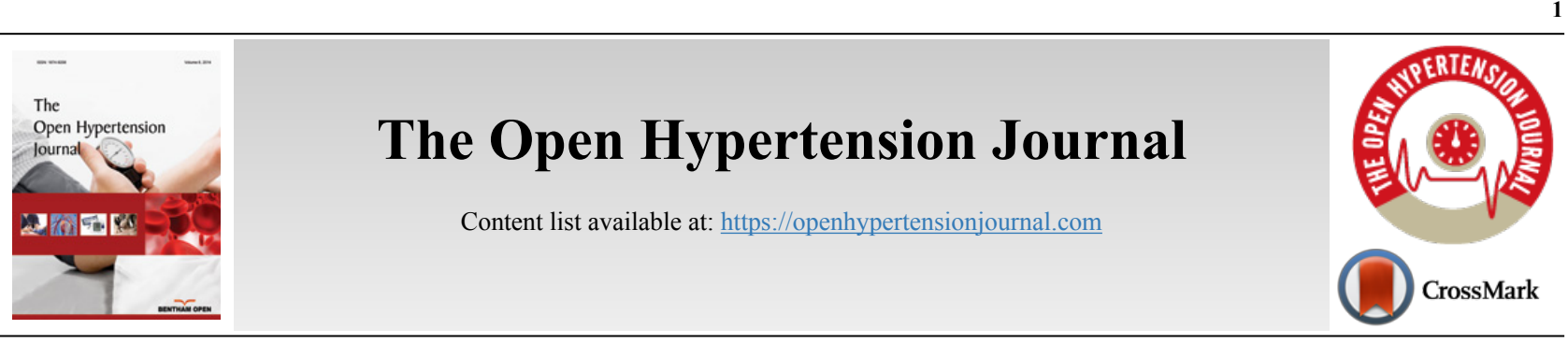

RESEARCH ARTICLE

\title{
Hypertension and its Relation with Waist to Hip Ratio in Women Referred to Bojnurd Urban Health Centers in 2014
} \author{
Andishe Hamedi ${ }^{4, *}$ \\ ${ }^{1}$ Department of Epidemiology \& Biostatistics, North Khorasan University of Medical Sciences, Iran \\ ${ }^{2}$ Department of Public Health, North Khorasan University of Medical Sciences, Iran \\ ${ }^{3}$ Department of Cardiology, North Khorasan University of Medical Sciences, Iran \\ ${ }^{4}$ Department of Nursing, North Khorasan University of Medical Sciences, Iran
}

Hossein Lashkardoost ${ }^{1}$, Fateme Hoseyni ${ }^{2}$, Elham Rabbani ${ }^{2}$, Farzane Q Moqadam ${ }^{2}$, Leila Hosseini ${ }^{3}$, Salimeh Azizi $^{4}$ and

\begin{abstract}
:
Introduction:

North Khorasan province has one of the highest rates of hypertension. One of the main causes of hypertension is obesity. Obesity is one of the most important public health problems around the world as a risk factor for non-communicable diseases. Since a similar study was not conducted in Bojnurd, we examined the relationship between waist to hip ratio with hypertension.

\section{Methods:}

The present cross-sectional study was conducted on women referring to Bojnurd health centers. To analyze the data, we used t-test, chi-square, multiple logistic regression and Pearson correlation in Stata 12 software.

Results:

In this cross-sectional study, the prevalence of systolic blood pressure was $14.78 \%$ and diastolic blood pressure was $15.65 \%$. So waist to the hips showed the highest correlation with the changes in hypertension.

Conclusion:

There are significant relationships between the age and the number of pregnancies with the risk of hypertension. Since a significant percentage of people are unaware of the existence of hypertension, changing diet and having regular physical activity along with social support is an important strategy.
\end{abstract}

Keywords: Hypertension, Waist circumference, Waist to hip ratio, Obesity, Waist to height ratio, BMI.

Article History

Received: August 06, 2018

Revised: January 26, 2019

Accepted: April 17, 2019

\section{INTRODUCTION}

Hypertension is a global disease with a high prevalence in worldwide. Hypertension is also one of the three major risk factors for global burden of disease following tobacco and alcohol use [1]. One of the main causes of hypertension is obesity [2]. Obesity is defined as BMI $\geq 30 \mathrm{~kg} / \mathrm{m} 2$ and excessive or abnormal accumulation of fat in the body tissue [3]. The prevalence of obesity in the elderly has steadily increased [4-6]. Obesity is one of the most important public

\footnotetext{
* Address correspondence to this author at Department of Nursing, North Khorasan University of Medical Sciences, Iran; Tel:+989171164918;

E-mail: ahameedi1364@gmail.com
}

health problems around the world as a risk factor for noncommunicable diseases [7]. One billion people are affected. Obesity increases the risk of hypertension [2]. The general or central distribution of body fat is associated with hypertension [8]. Obesity and hypertension are also a risk factor for cardiovascular disease, which creates significant economic burdens, especially in developing countries [9]. World Health Organization (WHO) reports that one in six adults is obese and one in three has hypertension [10]. The prevalence of high hypertension in low and middle income countries has also been reported more than in high-income countries. Also, the number of people whose hypertension is undiagnosed or untreated or have uncontrolled hypertension is higher in low and middle 
income countries [11]. The prevalence of hypertension in the Iranian population of $25-64$ years old is $22.1 \%$ [12]. Because human populations are leading to higher age and obesity, choosing the best measure to monitor the complications of obesity in the population is very important. Obesity can be determined by anthropometric indices such as BMI, WC, waist to hip ratio (WHR), and waist to height ratio (WHtR). The most common indicator used to measure obesity is the Body Mass Index (BMI). But this indicator does not indicate the distribution of central fat, while WHR is used as an alternative to determine the central distribution of obesity $[13,14]$. Therefore, identification of risk factors associated with hypertension and the adoption of initial prevention methods is required to determine the relationship between obesity and hypertension. North Khorasan Province has one of the highest rates of hypertension. Also, North Khorasan Province has the first ranking of provinces in terms of population-related fraction of hypertension due to obesity in women [15]. So using simple and inexpensive methods to diagnose obesity, and especially the distribution of obesity in the body, can greatly help identify people at risk for chronic diseases such as hypertension. Since a similar study was not conducted in Bojnurd, we examined the relationship between waist to hip ratio with hypertension.

\section{MATERIALS AND METHODS}

This article was approved by the code "93P767" in North Khorasan University of Medical Sciences, Iran. The present study is a cross-sectional study and the statistical population is women referring to Bojnurd health centers. To estimate sample size considering the prevalence of hypertension in the proportion of $30 \%$, accuracy of 0.06 and confidence level of $95 \%$, we examined 230 people. We chose health centers from a multi-stage sampling approach and by using a simple random sampling, we selected participants from their health records for the study see Fig. (1) then, care manager conducted the coordination (on a telephone) for mothers who were willing to participate in the study and she measured the anthropometric indices in the health center. Initial evaluation and follow up was done by the care manager to determine the basic indicators of health and behavioral measures. In managing individuals care managers used standard tools to improve outcomes. Inclusion criteria for case groups who had hypertension were all women (married) referred to health centers, who were willing to participate in the study, and diagnose as new case of hypertension, aged over 30 , not having a history of cardiovascular disease, diabetes, kidney disease. Exclusion criteria included not having a history of diet and exercise therapy to control or reduce weight gain. Inclusion and exclusion criteria in control group were considered, as in the case group, with the exception of their absence of hypertension. After obtaining satisfaction, the questions were asked by the trained person using a questionnaire and an interview. Each participant was interviewed about information including demographic characteristics (age, number of pregnancy, occupation, level of education, regular exercise (Having regular physical activity 150 minutes in week)). The waist circumference was measured on the part of the abdomen between the chest and hips with a minimum of clothing using a 0.1 meter precision with no pressure on the pelvic range, the hip circumference was calculated similar to the waist circumference with one meter in the widest hips section. The waist to hip ratio was then calculated from divided waist to hip. Waist to hip ratio $0.8 \leq$ in women was defined for abdominal obesity. We measured hypertension, in the left arm twice at the heart rate. The position of the individual in the sitting position was measured after 5 minutes of rest using an electronic device Omron (kyoto, Japan). Do not eat tea, coffee or using cigarette for half an hour before measuring hypertension. Systolic blood pressure (SBP) and Diastolic blood pressure (DBP) were calculated as the mean of these two measurements. Persons with systolic blood pressure $\geq 140 \mathrm{~mm} \mathrm{Hg}$ or diastolic pressure $\geq 90$, were considered as people with hypertension. To analyze the data, we used descriptive statistics tables and chi-square test, Pearson correlation and multiple logistic regression in STATA $^{12}$ software.

\section{RESULTS}

In this cross-sectional study, 230 women were enrolled in the study. The mean age of women participating in the study was $41.1 \pm 15.2$ years, with an average pregnancy rate of $3 \pm$ 0.14 . The prevalence of high systolic blood pressure was $14.78 \%(\mathrm{CI}=10.45-20)$ and high diastolic blood pressure $15.65 \%$ with confidence interval $(\mathrm{CI}=11.2-21)$. Table 1 shows the mean and standard deviation of anthropometric indices and its relation with hypertension. The correlation between anthropometric indices and systolic and diastolic blood pressure is shown in Table 2. Hypertension risk factors are shown in Table 3. As we see in the table, there is a significant relationship between the age and the number of pregnancies with the risk of hypertension.

\section{DISCUSSION}

Prevalence of hypertension varies from one country to another, from $10 \%$ to over $60 \%$ in different countries[16]). In the present study, the prevalence of hypertension is $14.78 \%$, which is different from other studies in different parts of Iran. Different studies have reported the prevalence of hypertension $13.7 \%$ and $19.4 \%$, respectively, which can be attributed to age differences and differences in geographical locations [17, 18]. A different outbreak of hypertension has been reported in other parts of the world. A study conducted by Chua has shown that the prevalence of hypertension is $22.5 \%$ [10].

In the present study, there was a significant correlation between anthropometric indices of central obesity such as WC, WHR with hypertension. The results of such studies are consistent with this study. Various studies have also shown that there is a strong correlation between the WHR index and hypertension, especially in women, which can be attributed to the differences in the effect of hormones on the distribution of body fat in women [19]. Several studies have reported an increase in the incidence of hypertension and its consequences, especially in women in developing countries, including Iran. The present study also suggests a high prevalence of hypertension in women. But such studies have also shown that the anthropometric index of WC has a strong and significant relationship with hypertension, it means that central obesity plays more effective role in hypertension than general obesity. 


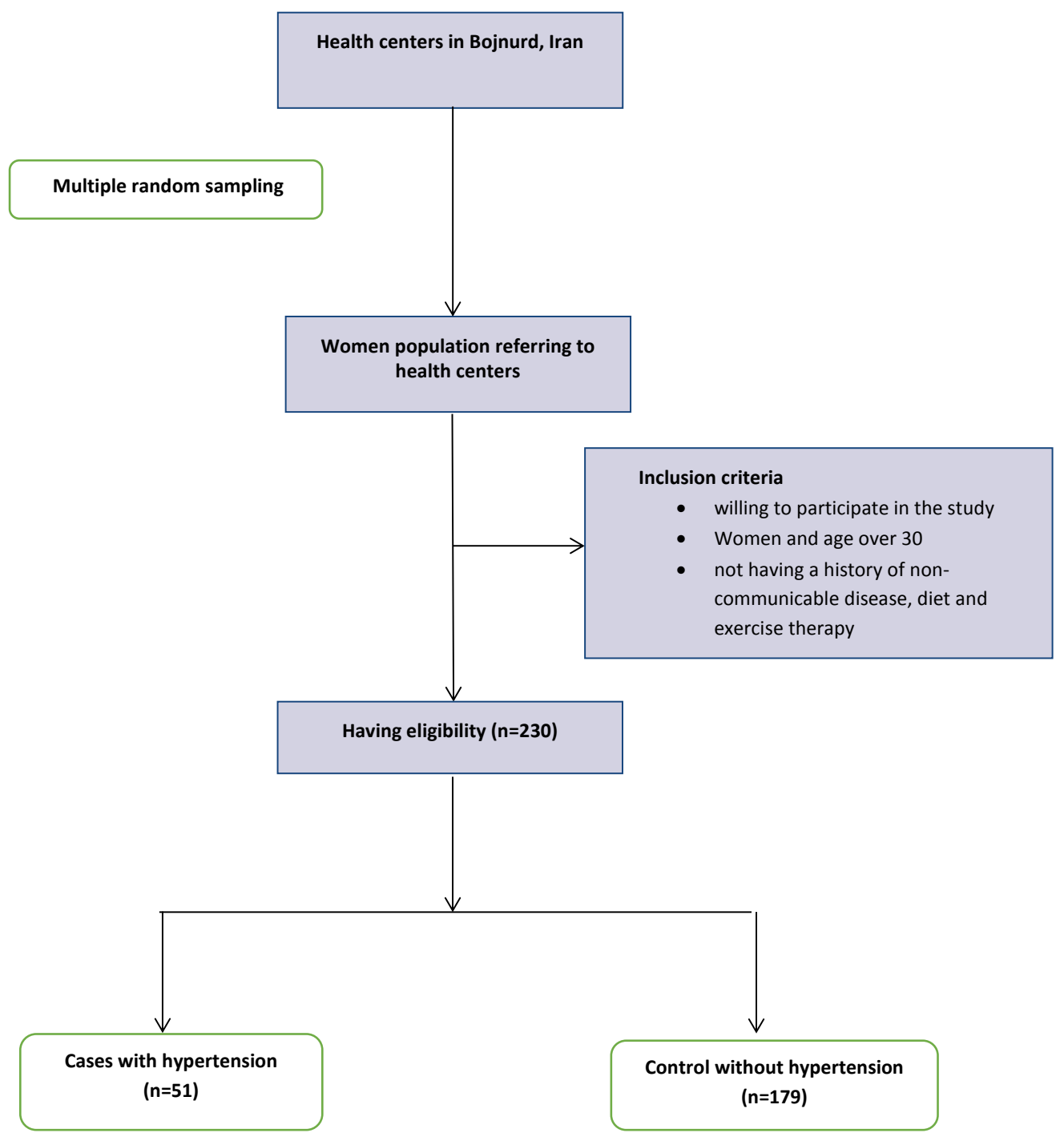

Fig. (1). Multiple random sampling Health centers in Bojnurd, Iran.

Table 1. Anthropometric parameters indicating the type of obesity and its relationship with hypertension.

\begin{tabular}{|c|c|c|c|}
\hline Anthropometric indices & $\mathbf{M} \pm$ SD in cases & $\begin{array}{c}\mathbf{M} \pm \text { SD in } \\
\text { controls }\end{array}$ & P-value \\
\hline Waist circumference & $101.6 \pm 9.7$ & $92.06 \pm 13.1$ & $<0.001$ \\
\hline Hip circumference & $108.7 \pm 8.8$ & $104.8 \pm 9.3$ & 0.008 \\
\hline Waist to hip ratio & $0.87 \pm 0.07$ & $0.93 \pm 0.06$ & $<0.001$ \\
\hline
\end{tabular}

Table 2. Correlation between anthropometric indices, systolic and diastolic blood pressure.

\begin{tabular}{|c|c|c|c|c|}
\hline $\begin{array}{c}\text { Anthropometric } \\
\text { indices }\end{array}$ & $\begin{array}{c}\text { Correlation } \\
\text { between } \\
\text { systolic blood } \\
\text { pressure }\end{array}$ & P-value & $\begin{array}{c}\text { Correlation } \\
\text { between } \\
\text { diastolic } \\
\text { blood } \\
\text { pressure }\end{array}$ & P-value \\
\hline Waist circumference & -0.30 & $<0.001$ & -0.22 & 0.001 \\
\hline Hip circumference & -0.13 & 0.04 & -0.11 & 0.08 \\
\hline Waist to hip ratio & -0.34 & $<0.001$ & -0.25 & $<0.001$ \\
\hline
\end{tabular}

Somehow, WC is a better predictor of the risk of hypertension that contradicts with this study $[8,20]$. In this study waist to the hips showed the highest correlation with the changes in hypertension.

In the present study, there was no significant relationship between regular exercise and hypertension. Such studies have reported similar results [21,22]. these studies have reported an inverse and significant relationship between regular physical activity and the risk of hypertension [23]. Some Studies have shown that having 5 times a week for 30 minutes of physical activity reduces the risk of hypertension. In this study few people in the two groups reported having exercised in their leisure time. So that people who do not have physical activity in the day are twice as susceptible to have higher hypertension.

In this study, age has a major risk in hypertension. The highest frequency of hypertension was in the age group of 50-60 and more than 60 years. The prevalence of hypertension increases with age, which can be justified by physiological changes in the coronary arteries of older ages. Such studies have reported similar results $[17,24]$. But such a study did not 
Table 3. Multiple logistic regression of hypertension risk factors in the two study groups.

\begin{tabular}{|c|c|c|c|c|c|}
\hline \multicolumn{2}{|c|}{ Variables } & \multirow{2}{*}{\begin{tabular}{|c|}
$\begin{array}{c}\text { Frequency and percentage in } \\
\text { case group }\end{array}$ \\
$4(7.8)$ \\
\end{tabular}} & \multirow{2}{*}{$\begin{array}{c}\begin{array}{c}\text { Frequency and percentage in } \\
\text { control group }\end{array} \\
67(37.4) \\
\end{array}$} & \multirow{2}{*}{$\begin{array}{c}\begin{array}{c}\text { Odds ratio and confidence } \\
\text { interval }\end{array} \\
1 \\
\end{array}$} & \multirow[t]{2}{*}{ P-value } \\
\hline \multirow{5}{*}{ Age } & $<30$ & & & & \\
\hline & $30-40$ & $7(13.7)$ & $55(30.7)$ & $2.1(0.5-7.6)$ & 0.24 \\
\hline & $40-50$ & $10(19.6)$ & $19(10.6)$ & $8.8(2.4-31.2)$ & 0.001 \\
\hline & $50-60$ & $15(29.4)$ & $22(12.3)$ & $11.4(3.4-38.05)$ & $<0.001$ \\
\hline & $>60$ & $15(29.4)$ & $16(8.9)$ & $15.7(4.5-53.7)$ & $<0.001$ \\
\hline \multirow{3}{*}{$\begin{array}{l}\text { Number of } \\
\text { pregnancy }\end{array}$} & $<=2$ & $8(15.7)$ & $97(54.2)$ & 1 & \\
\hline & $2-5$ & $28(54.9)$ & $68(38)$ & $4.9(2.1-11.6)$ & $<0.001$ \\
\hline & $>5$ & $15(29.4)$ & $14(7.8)$ & $12.9(4.6-36.2)$ & $<0.001$ \\
\hline \multirow{2}{*}{ Occupation } & Housewife & $45(88.2)$ & $151(84.4)$ & 1 & \\
\hline & Employee & $6(11.8)$ & $28(15.6)$ & $0.7(0.2-1.8)$ & 0.49 \\
\hline \multirow{3}{*}{ Level of Education } & Under diploma & $39(76.5)$ & $106(59.2)$ & 1 & \\
\hline & Diploma & $8(15.7)$ & $41(22.9)$ & $0.5(0.2-1.2)$ & 0.14 \\
\hline & Academic & $4(7.8)$ & $32(17.9)$ & $0.3(0.1-1.02)$ & 0.05 \\
\hline \multirow{2}{*}{ Regular Exercise } & No & $46(90.2)$ & $161(89.9)$ & 1 & \\
\hline & Yes & $5(9.8)$ & $18(10.1)$ & $0.9(0.3-2.7)$ & 0.95 \\
\hline
\end{tabular}

*Significant at $95 \%$ confidence level

report a significant relationship between age and hypertension which may be due to differences in the age group of the study [25].

The present study shows that the number of pregnancies is one of the factors that increases the blood pressure in women. Such studies have reported similar results [26].

In this study, there was no significant relationship between female's occupation and their educational level with hypertension. But such studies have shown that the prevalence of hypertension is related with occupational and educational level that is contradict with this study [22, 27].

The study also has limitations such as: the lack of measurement of the association of chronic diseases such as diabetes, dyslipidemia with hypertension and its relation with anthropometric indicators. Also, this study is a cross-sectional study and the cause-effect relationship can't be determined between the risk factors of the disease. As a result, attention to larger and prospective studies to determine the relationship between central obesity and the risk of hypertension and related factors is necessary.

\section{CONCLUSION}

In this study, anthropometric indices such as WHR were significantly higher in subjects with hypertension than in control group. This shows the importance of weight control in preventing chronic diseases, especially hypertension. Obesity is an important issue and needs urgent attention. Changing diet and having regular physical activity along with social support is an important strategy to prevent obesity and the subsequent hypertension.

\section{ETHICS APPROVAL AND CONSENT TO PARTICIPATE}

The study was approved by the Ethical Committee of North Khorasan University of Medical Sciences, Iran with the code "93P767".

\section{HUMAN AND ANIMAL RIGHTS}

No animals were used in this research. All human research procedures followed were in accordance with the ethical standards of the committee responsible for human experimentation (institutional and national), and with the Helsinki Declaration of 1975, as revised in 2013.

\section{CONSENT FOR PUBLICATION}

Informed consent was obtained from all the participants.

\section{CONFLICT OF INTEREST}

The authors declare no conflict of interest, financial or otherwise.

\section{ACKNOWLEDGEMENTS}

The authors would like to appreciate all subjects, who participated in the present study.

\section{REFERENCES}

[1] Stephen S, Vos T, Flaxman AD, Danaei G, Shibuya K, Adair-Rohani $\mathrm{H}$, et al. A comparative risk assessment of burden of disease and injury attributable to 67 risk factors and risk factor clusters in 21 regions, 1990-2010: A systematic analysis for the Global Burden of Disease Study 2010 2017; 2010: 2017.

[2] Huxley R, Mendis S, Zheleznyakov E, Reddy S, Chan J. Body mass index, waist circumference and waist:hip ratio as predictors of cardiovascular risk: A review of the literature. Eur J Clin Nutr 2010; 64(1): 16-22.

[http://dx.doi.org/10.1038/ejen.2009.68] [PMID: 19654593]

[3] Chang C-J, Wu C-H, Chang C-S, et al. Low body mass index but high percent body fat in Taiwanese subjects: Implications of obesity cutoffs. Int J Obes Relat Metab Disord 2003; 27(2): 253-9. [http://dx.doi.org/10.1038/sj.ijo.802197] [PMID: 12587007]

[4] Babu GR, Murthy GVS, Ana Y, et al. Association of obesity with hypertension and type 2 diabetes mellitus in India: A meta-analysis of observational studies. World J Diabetes 2018; 9(1): 40-52. [http://dx.doi.org/10.4239/wjd.v9.i1.40] [PMID: 29359028]

[5] Mathus-Vliegen EM, Basdevant A, Finer N, et al. Prevalence, pathophysiology, health consequences and treatment options of obesity in the elderly: A guideline. Obes Facts 2012; 5(3): 460-83. [http://dx.doi.org/10.1159/000341193] [PMID: 22797374] 
[6] Elia M. Obesity in the elderly. Obes Res 2001; 9(S11)(Suppl. 4): 244S-8S.

[http://dx.doi.org/10.1038/oby.2001.126] [PMID: 11707549]

[7] Health Mo. Welfare, Control KCfD, Prevention. Korea health statistics 2012: Korea National Health and Nutrition Examination Survey (KNHANES V $\square 3$ ) Ministry of Health and Welfare/Korean Centers for Disease Control and Prevention Sejong/Cheongj 2013.

[8] Taing KY, Farkouh ME, Moineddin R, Tu JV, Jha P. Age and sexspecific associations of anthropometric measures of adiposity with blood pressure and hypertension in India: A cross-sectional study. BMC Cardiovasc Disord 2016; 16(1): 247.

[http://dx.doi.org/10.1186/s12872-016-0424-y] [PMID: 27905876]

[9] Bloom DE, Cafiero E, Jané-Llopis E, et al. The global economic burden of noncommunicable diseases. Program on the Global Demography of Aging 2012.

[10] Chua EY, Zalilah MS, Haemamalar K, Norhasmah S, Geeta A. Obesity indices predict hypertension among indigenous adults in Krau Wildlife Reserve, Peninsular Malaysia. J Health Popul Nutr 2017; 36(1): 24 .

[http://dx.doi.org/10.1186/s41043-017-0102-4] [PMID: 28545536]

[11] Organization WH. A global brief on hypertension: Silent killer, global public health crisis: World Health Day 2013. World Health Organization 2013.

[12] Malekzadeh MM, Etemadi A, Kamangar F, et al. Prevalence, awareness and risk factors of hypertension in a large cohort of Iranian adult population. J Hypertens 2013; 31(7): 1364-71.

[http://dx.doi.org/10.1097/HJH.0b013e3283613053] [PMID: 23673348]

[13] Zhou Z, Hu D, Chen J. Association between obesity indices and blood pressure or hypertension: which index is the best? Public Health Nutr 2009; 12(8): 1061-71.

[http://dx.doi.org/10.1017/S1368980008003601] [PMID: 18778533]

[14] Browning LM, Hsieh SD, Ashwell M. A systematic review of waistto-height ratio as a screening tool for the prediction of cardiovascular disease and diabetes: $0 \cdot 5$ could be a suitable global boundary value. Nutr Res Rev 2010; 23(2): 247-69.

[http://dx.doi.org/10.1017/S0954422410000144] [PMID: 20819243]

[15] Mohammadi M, Mirzaei M, Barati H. Population Attributable Fraction of Hypertension Associated with Obesity in Elderly of Northwest Iran. Population 2017; 12(3)

[16] Lawes CM, Vander Hoorn S, Rodgers A. Global burden of bloodpressure-related disease, 2001. Lancet 2008; 371(9623): 1513-8. [http://dx.doi.org/10.1016/S0140-6736(08)60655-8] [PMID: 18456100]

[17] Fazizi F, Esmaillzadeh A, Mirmiran P. Obesity and cardiovascular disease risk factors in Tehran adults: A population-based study 2004.
[18] Kearney PM, Whelton M, Reynolds K, Whelton PK, He J. Worldwide prevalence of hypertension: A systematic review. J Hypertens 2004; 22(1): 11-9.

[http://dx.doi.org/10.1097/00004872-200401000-00003] [PMID: 15106785]

[19] Feldstein CA, Akopian M, Olivieri AO, Kramer AP, Nasi M, Garrido D. A comparison of body mass index and waist-to-hip ratio as indicators of hypertension risk in an urban Argentine population: A hospital-based study. Nutr Metab Cardiovasc Dis 2005; 15(4): 310-5. [http://dx.doi.org/10.1016/j.numecd.2005.03.001] [PMID: 16054556]

[20] Collaboration ERF. Adult height and the risk of cause-specific death and vascular morbidity in 1 million people: Individual participant meta-analysis. Int J Epidemiol 2012; 41(5): 1419-33.

[http://dx.doi.org/10.1093/ije/dys086] [PMID: 22825588]

[21] Kim H-K, Takahashi M, Konishi M, et al. P-46 Effects of increased daily physical activity on blood lipids and blood pressure in older adults. BMJ Publishing Group Ltd and British Association of Sport and Exercise Medicine 2016.

[http://dx.doi.org/10.1136/bjsports-2016-097120.99]

[22] Sarikhani Y, Heydari ST, Emamghorashi F, Jafari F, Tabrizi R, Karimpour S, et al. Associated Factors and Standard Percentiles of Blood Pressure among the Adolescents of Jahrom City of Iran. Int J Pediatr 2014; 2017: 2017.

[23] Organization WH. 8-11.Geneva: Waist circumference and waist-hip ratio: Report of a WHO expert consultation 2008; pp. Geneva: Waist circumference and waist-hip ratio: Report of a WHO expert consultation 2011; pp.

[24] Azizi F, Ghanbarian A, Madjid M, Rahmani M. Distribution of blood pressure and prevalence of hypertension in Tehran adult population: Tehran Lipid and Glucose Study (TLGS), 1999-2000. J Hum Hypertens 2002; 16(5): 305-12.

[http://dx.doi.org/10.1038/sj.jhh.1001399] [PMID: 12082490]

[25] Afrifa-Anane E, Agyemang C, Codjoe SNA, Ogedegbe G, de-Graft Aikins A. The association of physical activity, body mass index and the blood pressure levels among urban poor youth in Accra, Ghana. BMC Public Health 2015; 15(1): 269.

[http://dx.doi.org/10.1186/s12889-015-1546-3] [PMID: 25881047]

[26] Amirkhizi F, Siasi F. Minaee s, Jalali M, Dorostimotlagh A, CHamri M. Study of blood pressure in rural women in Kerman province and its relationship with anthropometric status. J Lorestan University Med Sci 2008; 10(2)

[27] Erem C, Arslan C, Hacihasanoglu A, et al. Prevalence of obesity and associated risk factors in a Turkish population (trabzon city, Turkey). Obes Res 2004; 12(7): 1117-27.

[http://dx.doi.org/10.1038/oby.2004.140] [PMID: 15292476]

(C) 2019 Lashkardoost et al.

This is an open access article distributed under the terms of the Creative Commons Attribution 4.0 International Public License (CC-BY 4.0), a copy of which is available at: https://creativecommons.org/licenses/by/4.0/legalcode. This license permits unrestricted use, distribution, and reproduction in any medium, provided the original author and source are credited. 